\title{
“SOMOS OTROS, PERO RECORDAMOS DE DÓNDE VENIMOS COMO ZOQUES": APROXIMACIONES A LAS GENERACIONES POST-ERUPCIÓN Y SUS DINÁMICAS REGIONALES
}

\section{"We Are Others, But We Remember Where We \\ Come From as Zoques": Approaches to Post- ERUPTION GENERATIONS AND ITS REgIONAL DyNAMICS}

\section{Marina Alonso Bolaños ${ }^{1}$}

Resumen: La experiencia indígena de la erupción de El Chichonal en 1982 puso en marcha la memoria colectiva para dotar de nuevo sentido al espacio geográfico y social. Los damnificados de los pueblos zoques destruidos fueron reubicados en nuevos asentamientos en municipios chiapanecos, proceso que resultó en la construcción de nuevos espacios geográficos y en la generación de diversas dinámicas socioculturales en las regiones, fundamentalmente en lo que respecta al papel de los nuevos sujetos sociales.

En tanto que no existen historias lineales — de causas y efectos-, el devenir de los zoques debe ser abordado como un proceso de múltiples historias entrelazadas. Este artículo explora la correlación entre un episodio reciente de la historia ambiental y los procesos socioculturales suscitados en la actualidad en tres zonas de Chiapas con población de origen zoque, en particular la generación post-erupción: Nuevo Carmen Tonapac, en el municipio de Chiapa de Corzo, la Selva Negra y la Selva Lacandona.

\footnotetext{
${ }^{1}$ Etnóloga. Maestra en Antropología. Doctora en Historia por El Colegio de México. Investigadora Titular del Instituto Nacional de Antropología e Historia. Temas de investigación: antropología e historia de los zoques de Chiapas y Oaxaca, procesos socioambientales, espacio y expresiones musicales.

Correo electrónico: marina_alonsob@hotmail.com

Fecha de recepción: 0710 15; Fecha de aceptación: 200515.
} 
Palabras clave: El Chichonal, zoques, dinámicas regionales, jóvenes indígenas, memoria colectiva.

Abstract: The indigenous people's experience of Chichonal Volcano eruption in 1982 prompted the collective memory to give new meaning to the geographical and social space. Destroyed villages victims were relocated in new settlements in Chiapas, this process has resulted in the construction of new geographical areas and different sociocultural dynamics, in particular the role of new social actors.

As there is non-linear historic development —of causes and effects-, Zoquean people's becoming should be studied as a process of connected multiple stories. This article explores the correlation among the recently episode of the environmental history and sociocultural processes, particularly the post-eruption generation, in three Zoquean regions of Chiapas: Chiapa de Corzo, Selva Negra and Lacandon Forest.

Keywords: El Chichonal, Zoquean People, Regional Dynamics, Indigenous Young People, Collective Memory.

Mapa 1. Área Zoque en el estado de Chiapas

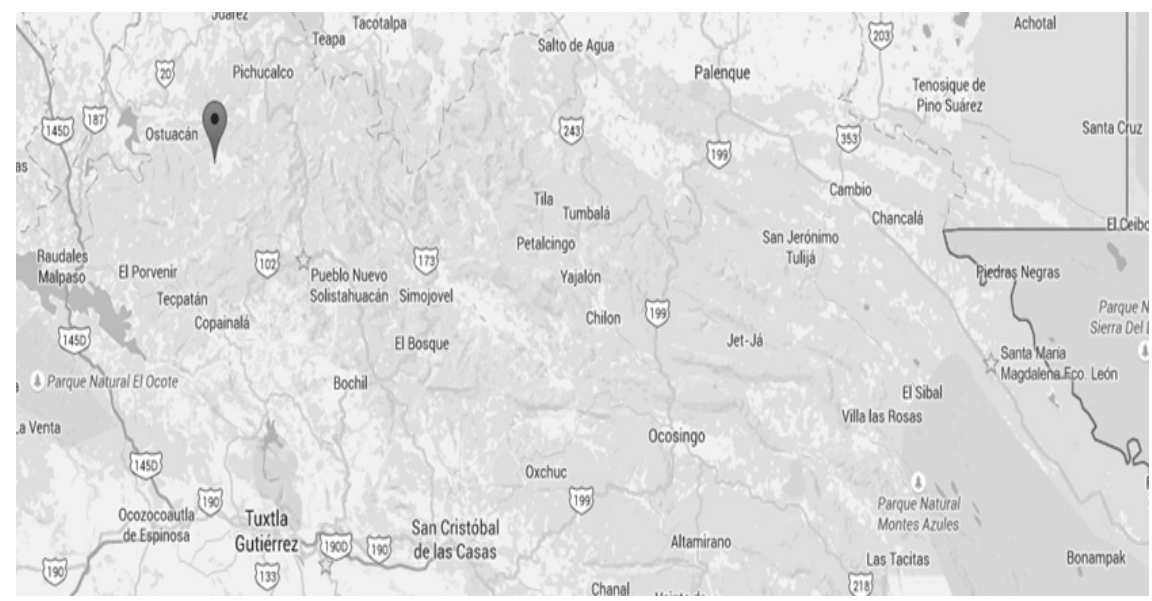

Fuente: Google maps. 


\section{La heterogeneidad a prueba: los zoques en diferentes contextos regionales}

Para abordar el papel de la generación post-erupción en el devenir de los zoques dispersados por el fenómeno natural se exploran tres contextos regionales ${ }^{2}$ donde se correlaciona un episodio de la historia ambiental -la erupción del volcán- con diversos procesos socioculturales en tres zonas. Cabe mencionar que considero como generación posterupción a los jóvenes de origen zoque quienes siendo muy pequeños fueron desplazados por la erupción o bien nacieron después de ésta. Me refiero aquí a las generaciones y a los jóvenes en tanto categorías sociales que se determinan, en menor medida, por la edad biológica que por los significados del ser joven en tanto edad social que tiene en sus contextos. Este segmento de la población pasa por un estatus transitorio, esto es, "los sujetos no pertenecen a la categoría sino que la atraviesan” (Rosemberg, 2013: 251).

En este caso abordaré a jóvenes de: a) el ejido Nuevo Esquipulas Guayabal, en Rayón, municipio Selva Negra, con problemáticas relacionadas con el deterioro ambiental y conflictos agrarios, b) el ejido Nuevo Carmen Tonapac, municipio Chiapa de Corzo, en donde los jóvenes viven los cambios suscitados por el impacto de la proximidad geográfica y política con la cabecera municipal y con la capital del estado, y 3) Nuevo Francisco León, en la Selva Lacandona, con problemáticas en torno a los conflictos intracomunitarios y de índole agraria.

Con respecto a los contextos regionales, debido a las complejas dinámicas de los actuales asentamientos habitados por población de origen zoque, ${ }^{3}$ los territorios se han caracterizado por ser discontinuos $y$, en varios casos, por encontrarse en procesos de fragmentación. Esto ha dado como resultado que a lo largo de la historia hayan coexistido diferentes regiones zoques. Probablemente, estose deba a que en el pasado, como indica el historiador Juan PedroViqueira (1998), los

\footnotetext{
2 Para este artículo he elegido estos tres casos porque resultan de la investigación etnográfica que desarrollo actualmente (Alonso et al., inédito).

${ }^{3}$ En este artículo utilizaré con el mismo sentido "población zoque" que "de origen zoque".
} 
caminos no comunicaban a todos los poblados entre sí y, por tanto, nunca surgió un centro comercial y político que pudiera aglutinar a la población zoque en una sola región. Los principales asentamientos urbanos se encontraban en las fronteras de dichas regiones. De manera que se conformaron zonas no homogéneas en cuyo interior había enclaves de zonas más pobres y aisladas.

Aunque antes de la erupción del volcán El Chichonal en 1982 las localidades zoques no estaban del todo inconexas, era posible delimitar la existencia de, al menos, tres grandes regiones diferenciadas entre sí. La primera integraba a los municipios de Ostuacán, Sunuapa, Francisco León, Chapultenango y Ocotepec, que sostenían vínculos con Ixtacomitán y Pichucalco. La segunda integraba a Tapalapa, Ocotepec, Pantepec, Rayón y Tapilula, y se relacionaba estrechamente con los municipios de Ixhuatán, Pueblo Nuevo Solistahuacán, Jitotol, y con la Depresión Central; y finalmente, la tercera, comprendía Copainalá, Chicoasén, Coapilla, Tecpatán, Ocozocoautla —también a Francisco León, Tapalapa y Ocotepec_-, relacionada con Tuxtla Gutiérrez, con el estado de Veracruz y con Tabasco.

Si bien dichas regiones son aún distinguibles después de la erupción, también se han modificado a partir de los nuevos vínculos que sostienen social, económica y políticamente con las cabeceras municipales y los centros regionales — que bien pueden coincidir con su cabecera o con la de otro municipio- de Chiapas o Tabasco. Cabe mencionar que no obstante los esfuerzos que el gobierno chiapaneco hizo en ese entonces por concentrar y retener a los damnificados poco después de la erupción, la dispersión de la población zoque de las localidades devastadas era extraordinaria. Muchas personas huyeron hacia diferentes puntos del noroeste de Chiapas, Veracruz, Oaxaca y Tabasco. Otros zoques regresaron a los lugares de origen en las zonas menos afectadas, y algunos grupos exigieron la creación de colonias agrícolas en sus mismos municipios y actuaron en consecuencia.

En efecto, como veremos a continuación, los damnificados de los pueblos destruidos fueron reubicados en nuevos asentamientos en municipios chiapanecos, proceso que dio como resultado la construcción de espacios geográficos y la emergencia de diversas 
dinámicas socioculturales, económicas y políticas. Algunas de estas nuevas dinámicas se relacionan con los conflictos por las tierras, las disputas por el poder y la agencia de la generación post-erupción ${ }^{4}$ como una nueva forma de ser joven indígena zoque. Para afirmar lo anterior, parto del hecho de que el espacio, al mismo tiempo que es un constructo social tiene un papel en la conformación de la sociedad, esto es, actúa sobre la vida social, la transforma, la configura, tal como lo advierten Hoffman y Salmerón: el espacio es "a la vez sustento, participante y resultado de la construcción de las sociedades" (Hoffman y Salmerón, 1997: 17).

Por su parte, la erupción puso en evidencia la vulnerabilidad de la población asentada en las estribaciones — dada su condición de marginación y pobreza - frente al peligro que implicaba la cercanía al volcán. Sin embargo, los zoques no sólo fueron víctimas de El Chichonal sino también de la intervención caótica de los diferentes organismos gubernamentales por la respuesta tardía y por las acciones improvisadas de éstos frente al fenómeno natural y sus múltiples consecuencias sociales, por ejemplo, el reacomodo de la población damnificada en nuevos asentamientos. ${ }^{5}$

Así, la diáspora de los zoques y la creación de asentamientos alejados de sus municipios históricos, como el reacomodo en la Selva Lacandona, fueron consecuencias brutales de la erupción. Sin embargo, los grupos afectados se sobrepusieron gracias a la emergencia de nuevas formas de organización social y a la recreación

\footnotetext{
${ }^{4}$ Incluyo en la misma categoría de generación post-erupción tanto a los géneros masculino y femenino, como a homosexuales. Cada uno de estos subgrupos tiene sus propias problemáticas en el seno de la sociedad chiapaneca, las cuales rebasan los fines de este artículo.

${ }^{5}$ Alrededor de 3,500 familias zoques fueron reubicadas en terrenos adquiridos por el gobierno de Chiapas en los municipios de Rayón, Tecpatán, Ostuacán, Pichucalco, Cintalapa, Chiapa de Corzo, Juárez y Ocosingo. Actualmente, población de origen zoque desplazada habita también en varias regiones del noroeste, centro y Selva Lacandona en Chiapas; Las Choapas en Veracruz, Sierra norte de Oaxaca, Calakmul en Quintana Roo, sur de Tabasco, viven en algunas colonias en Guadalajara, Jalisco y en barrios de Boston en los Estados Unidos. No incluyo en esta lista a la población de origen zoque que ha habitado en la selva de Los Chimalapas en Oaxaca porque no está directamente relacionada con la erupción de El Chichonal. Para abundar al respecto, véase Alonso, 2011.
} 
de mecanismos culturales que han otorgado sentido a su devenir. A su vez, procesos similares - aunque en contextos diferenciadoshan sucedido entre la población que retornó a sus regiones de origen para la recuperación y reconfiguración de su espacio, en particular de las tierras de cultivo y pastoreo, así como de los lugares sagrados y los referidos a aquellos seres sobrenaturales que los habitan. Empero, la erupción no afectó por igual a los pobladores de las diferentes regiones de origen zoque, ni siquiera a los habitantes de una misma localidad. De manera que las consecuencias del fenómeno natural: las transformaciones, las continuidades, los conflictos y los nuevos tejidos sociales que establecieron los zoques, fueron igualmente múltiples, tal como veremos a continuación.

\section{Jóvenes zoques en tres contextos regionales}

El primer caso al cual me referiré es el de los jóvenes zoques hijos de ejidatarios reubicados en el municipio de Rayón. He propuesto líneas antes que este municipio pertenecía a una región integrada por Tapalapa, Ocotepec, Pantepec, Rayón y Tapilula, relacionada con Ixhuatán, Pueblo Nuevo Solistahuacán y Jitotol. Precisamente, el bosque mesófilo de montańa conocido como la Selva Negra coincide con una parte de los territorios de estos municipios, excepto Ocotepec y Jitotol. Por su parte, Rayón es un pequeño municipio de 9,000 habitantes ${ }^{6}$ de distintos orígenes étnicos — más de 2,300 hablantes del zoque y 280 tsotsil, los demás son considerados población mestiza- que posee dos ejidos, uno de los cuales, Nuevo Esquipulas Guayabal, fue creado para los reubicados de Chapultenango. Una vez que estos ejidatarios y sus familias fueron reubicados y dotados de tierra en el nuevo ejido del municipio de Rayón - que los divide tan sólo una calle de la cabecera municipal—, sus antiguas parcelas en el municipio de Chapultenango pasaron legalmente a manos de otros ejidatarios, lo cual dio origen al conflicto en proceso ante el Tribunal Agrario. Recientemente, un grupo de ejidatarios del ejido Nuevo Esquipulas Guayabal, en Rayón, pidió a tsotsiles

\footnotetext{
${ }^{6}$ Información municipal en http://www.ceieg/chiapas.gob.mx. Consulta, noviembre de 2013.
} 
de Rincón Chamula, en Pueblo Nuevo Solistahuacán, ocupar terrenos del antiguo ejido en las laderas del volcán que aún consideran suyos.

Si bien los ejidatarios son los actores del conflicto, las familias en general sufren el problema de una forma u otra y, paradójicamente, los jóvenes estudiantes de bachillerato y los universitarios se encuentran más preocupados por el deterioro de la selva que por la defensa de tierras. Esto tiene una posible explicación en el hecho de que aunque el vínculo que sostienen con la tierra vaya más allá de poseerla, los jóvenes saben que difícilmente obtendrán parcelas porque éstas son insuficientes para ser distribuidas. Ni siquiera saben si alguno de sus hermanos las heredará. De manera que el deterioro ambiental, en general, figura en el imaginario de estos grupos juveniles como una época de crisis que definirá su futuro si no actúan para revertirlo.

De cara a ello, estos jóvenes han emprendido diversas acciones, una de las cuales ha sido la llamada "marcha ecológica" en contra de la habilitación del basurero municipal en la Selva Negra y como manifestación para frenar la contaminación del agua y la explotación indiscriminada de los recursos forestales. Muchas de estas actividades han sido promovidas desde el Colegio de Bachilleres de Chiapas (Cobach) que se ubica en la cabecera municipal, como parte de la materia que cursan sobre ecología, apoyado por los frailes franciscanos de la parroquia de Rayón; otras actividades han sido fomentadas por jóvenes artistas y promotores culturales del ejido Nuevo Guayabal:

[...] Por ejemplo, nos da coraje [el deterioro ambiental], (...) todos los manantiales estaban secos; no hay programas para el manejo de la basura y no sabemos qué hacer. Lo que hago es compartir las fotos, compartir en Facebook, hacer documentales y los subo a youtube (...), hablar de la tierra de cómo nuestros antepasados consideraban madre a la tierra. El proyecto es del pueblo no es de las instituciones. Lo movemos en las redes para dar a conocer nuestros trabajo (entrevista en Rayón, noviembre 2013). 
Foto 1. Motivo ecologista del pintor Saúl Kak en Nuevo Esquipulas

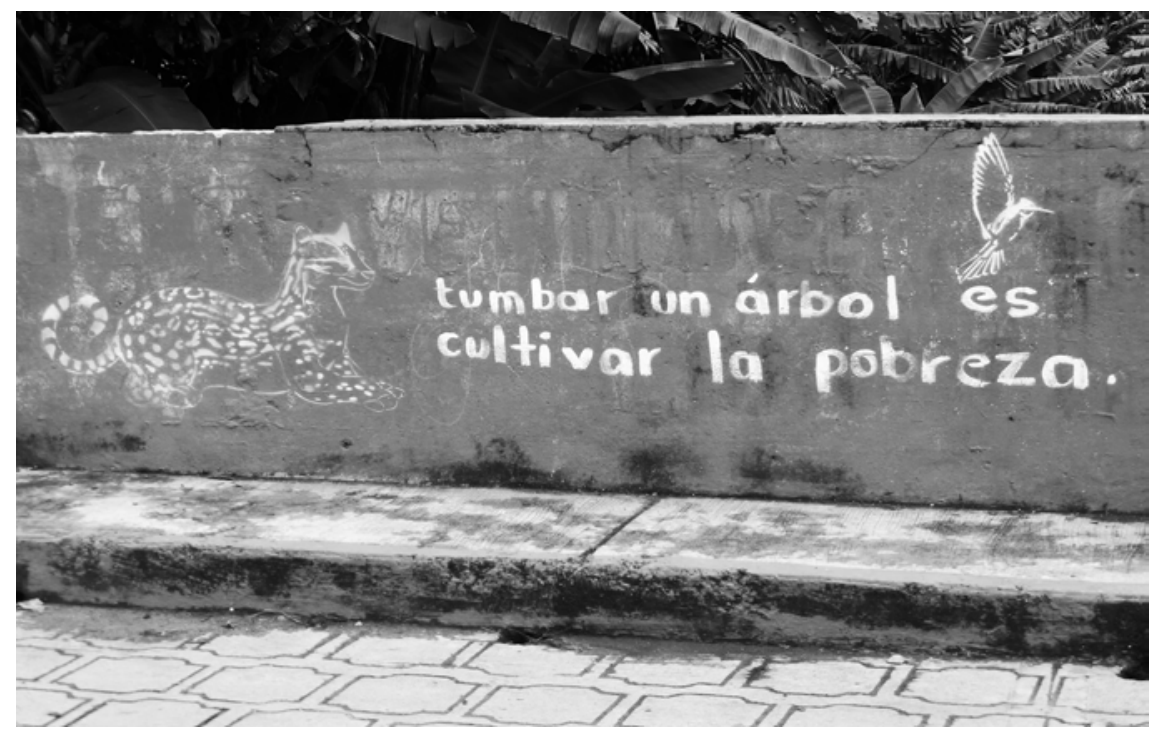

Fuente: Marina Alonso Bolaños, 2012.

El segundo caso que abordaré aquí corresponde a jóvenes descendientes de damnificados de la erupción del volcán El Chichonal reubicados en la colonia Nuevo Carmen Tonapac, dentro del municipio de Chiapa de Corzo. ${ }^{7}$ Durante muchos años los zoques de este lugar se mantuvieron al margen de la dinámica regional social, política y económica de Chiapa de Corzo. Sin embargo, fueron acercándose paulatinamente a la cabecera municipal —otrora lugar de tránsito o centro administrativo para resolver sus asuntos de la localidad_ - interesados por la celebración de la Fiesta Grande, ${ }^{8}$ sobre todo cuando se percataron de que podría ser una fuente de ingresos si cultivaban calabaza, pues el plato tradicional

7 Chiapa de Corzo es la cabecera del municipio del mismo nombre ubicada en la Depresión Central chiapaneca. De la población total $(87,603), 40 \%$ del municipio habita en esa ciudad. Y de acuerdo con el censo 2010 de Inegi, 3\% de los pobladores del municipio habla zoque o tzotzil.

${ }^{8}$ Fiesta chiapacorceńa celebrada en el mes de enero en honor al santo patrono San Sebastián. 
que se degusta durante los días de festejo es la "pepita con tasajo". 9 La calabaza de donde se obtiene la pepita era cultivada por las propias familias chiapacorceñas que preparaban el guiso para la Fiesta Grande, pero en la actualidad, la pepita se consigue en el municipio de Villaflores o bien se les compra a los intermediarios que la adquieren directamente de los productores de la colonia Grijalva y de los zoques de Nuevo Carmen Tonapac.

Actualmente los zoques de esta colonia de damnificados acuden a la celebración y algunos de ellos se suman al numeroso grupo de los danzantes parachicos durante los días festivos. A pesar de que inicialmente los chiapacorceños se referían a los zoques de manera sarcástica como los "chichonales", los zoques nacidos en el nuevo asentamiento se consideran a sí mismos como chiapacorceños y aseguran no ser objeto de discriminación alguna. "Pero... ¿en qué consiste ser zoque? ¿Acaso habría una manera de serlo?”, pregunté a un joven estudiante preocupado en determinar aquellos elementos o ámbitos de la vida social en los cuales pudiera radicar eso que suele denominarse como "identidad zoque". ${ }^{10} \mathrm{Al}$ respecto, varios jóvenes se han abocado al trabajo de promoción cultural y valorización de aquello que llaman "cultura e identidad zoque", consistente en el fomento al uso de la lengua, a las expresiones musicales y dancísticas, al conocimiento de la herbolaria para la curación, entre otros aspectos.

Sin embargo, es importante para estos jóvenes distinguir dos ámbitos de alteridad frente a los mestizos chiapacorceños de la cabecera. Dichas distinciones están en el uso del idioma zoque y en la forma cotidiana de vivir, particularmente en lo que respecta a la labor agrícola y en el vínculo que sostienen con el antiguo asentamiento donde nacieron sus padres. Paradójicamente, dada la cercanía a la ciudad de Tuxtla Gutiérrez, muchos jóvenes de Nuevo Carmen Tonapac han salido de

\footnotetext{
${ }^{9}$ Mole a base de pepita que se acompaña con tiras de carne seca o tasajo (Alonso, 2014). ${ }^{10}$ No es de interés en este artículo discutir el concepto de identidad en el contexto de los zoques. Varios autores han abundado al respecto (Lisbona, 2003 y 2006; Alonso, 2009). Se trata de identidades en permanente recomposición de acuerdo con las relaciones sociales que establecen en sus contextos presentes, pues como indica Bartolomé, la identidad es un concepto relacional, en la medida en que supone la definición de un grupo realizada en función del contraste con otro (Bartolomé, 1997: 46).
} 
la localidad para realizar estudios universitarios en instituciones de este tipo.

El tercer caso al cual me referiré brevemente es el de los zoques reubicados en el corredor de Santo Domingo en la Selva Lacandona -municipio de Ocosingo-, que fueron alrededor de 2,500 sobrevivientes de 11 poblados de Francisco León, el más destruido por el fenómeno natural. Las localidades de este municipio, como he indicado arriba, sostenían vínculos de diversa índole con los municipios aledańos de Ocotepec, Ostuacán, Sunuapa y Chapultenango, pero después de la erupción sólo unas cuantas familias del contingente de reubicados reactivaron estos lazos, particularmente con habitantes de Chapultenango.

Asimismo, desde su llegada a la Selva Lacandona, los zoques de Nuevo Francisco León establecieron alianzas con los ejidos vecinos ch’oles y tzeltales de Nuevo México, Nuevo Guerrero, Nuevo Petalcingo y Jerusalén, quienes se encontraban en un momento de crisis y gran movilización social por el decreto federal de 1972 en el cual se consignó el otorgamiento de más de 600,000 hectáreas de la selva a la Comunidad Lacandona, desconociendo la legitimidad de muchos asentamientos previos. A este problema se sumaron posteriormente otros, tales como la caída del precio del café, la desaparición del Instituto Mexicano del Café y la reforma salinista al artículo 27 de la Constitución en 1992 (Alonso, 2009).

En este contexto, los zoques de Nuevo Francisco León buscaron fortalecerseal interior de su comunidad, perolas autoridades reprodujeron las viejas prácticas de corrupción con que se habían afianzado en el antiguo ayuntamiento municipal al controlar los recursos financieros proporcionados por los programas oficiales de apoyo a damnificados. De manera que se fueron dando fracturas internas, y hacia fines de la década de 1980 surgió un joven liderazgo. Algunos de estos jóvenes habían sido alumnos en el albergue indigenista de Ocosingo, y también participaron en grupos de reflexión con los misioneros jesuitas. Así, este pequeño grupo, apoyado por redes políticas externas a la localidad y por la Misión Jesuita de Bachajón, luchó contra los viejos sectores de poder que se habían impuesto en el nuevo asentamiento. Esta generación post- 
erupción también contribuyó con los ejidatarios para exigir al gobierno del estado de Chiapas la titularidad de las tierras ejidales que les habían sido dotadas por el gobierno federal a su llegada a la Selva (ibídem).

$\mathrm{Si}$ bien esta generación post-erupción estuvo en gran medida ocupada en resolver conflictos agrarios y disputas internas, contribuyó a restablecer el tejido social fracturado y con el apoyo de los ejidatarios y sus familias puso en marcha mecanismos culturales para dotar de sentido al nuevo espacio. Por ejemplo, el fomento al uso de la lengua zoque, el restablecimiento del culto a los santos y la organización de la fiesta patronal de Magdalena, junto con la organización social que la sustenta, contribuyeron a sostener una idea de comunidad. En este caso, como en los anteriores, la memoria colectiva adquiere un papel preponderante toda vez que posibilita la construcción colectiva del recuerdo (Halbwachs, 2004) de quiénes fueron y de sus espacios sociales antes de la erupción, al mismo tiempo que se construye lo que estos desplazados por la erupción son ahora.

\section{Desgarrando los ropajes esencialistas de "lo zoque"}

Aquí se ha abandonado el modo de antes. La lengua no se olvidaba, pero hay muchos jóvenes que no hablan su lengua.

También de vestir cambia. (Testimonio en Rayón, mayo 2014.)

Hace cuatro décadas Bonfil (1995: 340) señalaba que "quienes se sienten indios en América, o son considerados como tales, forman un conjunto demasiado disímil”, quizá más diferenciado entre sí que con las poblaciones circundantes no indias, por tanto, la identidad india resulta de escaso valor heurístico. Evidentemente esta consideración aplicaría también para la noción de grupo etnolingüístico, empero, desde la perspectiva de los sujetos al apropiarse del concepto en el contexto de sus reivindicaciones de carácter sociopolítico - me refiero a la generación post-erupción—, la categoría "zoque", o bien 
"lo zoque", se puede considerar procesal y aparece en vinculación con ámbitos específicos.

Así, la heterogeneidad de las respuestas a mediano y a largo plazo frente a la catástrofe social generada por la erupción nos lleva a considerar que "lo zoque" se expresa en una lucha política en contra de la situación de vulnerabilidad, como señalan los zoques de Nuevo Francisco León: "en tiempo de la ceniza en Chichonal como en la selva seguimos manifestándonos”. Justamente en un contexto de crisis es que se genera una etnicidad estratégica resultado de un proceso de reflexividad. Uno de los casos en que se puede dar cuenta en la actualidad de cómo se reconfigura un "ser zoque" es el de los hombres y mujeres de la generación post-erupción que pretenden definir el futuro social, económico y cultural de la población de los municipios de origen zoque, a partir de un proceso de reflexión iniciado en 2012 acerca de lo que había significado la erupción en términos de catástrofe social; algunos de estos jóvenes, conformarían años después, en 2014, el Centro de Lengua y Cultura Zoque, A.C.

Desalentada por la actuación de las instituciones gubernamentales de Chiapas que la considera únicamente como víctima de la erupción, y que la fuerza de cierta forma a realizar actividades anuales para conmemorar el fenómeno natural, esta generación post-erupción se reconoce como heredera de la historia zoque y desplazada por El Chichonal, pero con la posibilidad de decidir sobre sus propias formas de recordar. Es decir, la forma en que construyen la memoria colectiva del ser zoque es definida de acuerdo con los aspectos que esta generación considera importantes. Así, existe un interés por la tradición oral y la recuperación de la memoria en torno al volcán a partir de otras formas posibles de comprender la erupción, sea desde una perspectiva idílica o demasiado cruda frente al pasado real -o ficticio-. Los relatos registrados encuentran otro sentido en el contexto de lo que este grupo asegura es la cosmovisión zoque.

Aunque el idioma constituye un aspecto fundamental, no resulta determinante para la autoadscripción, pues no hablantes del zoque se reconocen como tales si es que nacieron en el seno de una familia de dicho origen o bien en asentamientos del noroeste de Chiapas; en 
particular, buscan diferenciarse de su entorno mayance. Este aspecto remite a la reflexividad por parte de los actores acerca de la red de relaciones sociales $-\mathrm{y}$ de relaciones de poder-en las cuales está inserto y que le permiten reconocerse o no como zoque.

De manera que la despolitización de la categoría "zoque", pretendiendo ubicarla únicamente en el ejercicio lingüístico y en la victimización de los grupos afectados por la erupción, ha sido una limitante para explicar las dinámicas regionales donde cohabitan zoques con una gran diversidad de población de distintos orígenes étnicos, entre los que están las diferentes configuraciones socioculturales que solemos denominar población mestiza, como si se tratara de un grupo homogéneo, de una masa amorfa.

Detengámonos un momento sobre este punto, pues debo decir que, por lo general, los estudios antropológicos en torno a la población de origen zoque se han centrado en las relaciones sociales al interior de asentamientos y comunidades sin considerar su contraparte complementaria — como la denomina Pitarch—: la población mestiza. Aunque este autor lo ejemplifica para el caso de Los Altos y de las zonas pobres de San Cristóbal de Las Casas, la situación es similar en otras zonas pues indica que la línea que separa a mestizos de indígenas es permeable y existen espacios sociales en los cuales es difícil distinguir si se trata de unos $\mathrm{u}_{\text {otros }}{ }^{11}$ (Pitarch, 1995), tal como he indicado acerca de los zoques chiapacorceños, y como es el caso también de los zoques tapatíos ${ }^{12}$ que ha documentado Domínguez (2013: 34). De igual forma, si recurrimos en la historia zoque previa a la erupción del volcán nos encontraremos con el ámbito de las fincas donde los vínculos entre los dueños mestizos y peones zoques sostenían el asimétrico tejido social y de alguna manera permitían la reproducción de la vida campesina; con la erupción, más allá de las consecuencias del fenómeno natural en sí mismo, se desequilibraron dichas relaciones. La composición de las autoridades locales se modificó y las fincas desa-

\footnotetext{
${ }^{11}$ Véase también el texto clásico escrito en la década de 1970 por Julián Pitt-Rivers: "Palabras y hechos: los ladinos", en McQuown, N. y J. Pitt-Rivers (editores), Ensayos de antropología en la zona central de Chiapas, Instituto Nacional Indigenista, México, 1989 [1970].

${ }^{12}$ Los zoques que han emigrado a la ciudad de Guadalajara.
} 
parecieron, lo cual trajo como consecuencia que los zoques perdieran una fuente importante de trabajo que, a su vez, sustituyeron con la migración y la pluriactividad, liberándose del acasillamiento en que vivían en "los tiempos del Chichonal". ${ }^{13}$

Regresemos ahora al grupo de hombres y mujeres de la generación post-erupción que nos ocupa. En los últimos años ha emergido un movimiento peculiar que busca concentrar en una organización a hijos de desplazados y damnificados de distintas regiones de origen zoque. Hay que decir que, aunque se trata de un sector sumamente heterogéneo, el ser joven responde a ciertos patrones estereotipados por la sociedad y asumidos acríticamente por los mismos jóvenes. Por ejemplo, la fascinación por las tecnologías de la comunicación, los teléfonos celulares y las computadoras hace que los jóvenes que tienen acceso a los equipos y a Internet - que son relativamente pocoslos coloquen como los indicadores de diferencia intergeneracional. Señalan que si bien sus padres crecieron con la televisión, no fue lo mismo que estar inserto ahora en las redes sociales de comunicación y usar la telefonía celular actual. En pocos casos los medios han sido apropiados para el registro y denuncia de problemas ambientales, como se ha hecho en Rayón, o bien para la documentación de expresiones musicales diversas.

En mayo de 2014, el Centro de Lengua y Cultura Zoque, A.C. ${ }^{14}$ conformado en su mayoría por profesionistas de distintos campos, ${ }^{15}$ organizó el Primer Congreso Zoque en el municipio de Rayón, en el ejido de reubicación Nuevo Esquipulas Guayabal que se localiza junto a la cabecera municipal — los divide una calle-, para el cual convocó a habitantes de distintas regiones zoques para exponer en

\footnotetext{
${ }^{13}$ La situación que vivían los habitantes de las localidades zoques fue cuestionada pocos ańos antes de la erupción por algunas de las autoridades tradicionales — que no siempre estaban vinculadas con las municipales_-, y también por ciertos líderes morales de las riberas y colonias a quienes las autoridades municipales calificaban como "problemistas" (Alonso, 2011).

${ }^{14}$ El presidente de esta asociación civil es Fermín Ledesma Domínguez, maestro en Desarrollo Rural, originario de Chapultenango.

${ }^{15} \mathrm{Y}$ por algunos académicos en calidad de miembros honorarios, como la autora del presente artículo.
} 
mesas de trabajo acerca de los problemas que los aquejan: derechos agrarios y resolución de conflictos, situación de las mujeres, que incluye una discusión sobre las relaciones de género, educación y salud, y problemas ambientales.

A partir del encuentro, dicho Centro ha emprendido diversas tareas como frentes de lucha: el ejercicio de la lengua zoque - aunque se debata en torno a cuál variante debiera ser sistematizada y transmitida—, el fomento a las diversas expresiones artísticas: pintura, música, poesía y literatura, por ejemplo, a través del trabajo de Mikeas Sánchez, poetisa zoque, de Trinidad Cordero y de Saúl Kak, entre otros. Algunos jóvenes se desarrollan como promotores de la "cultura zoque", como Roberto Lorenzo y Trinidad Cordero, por tan sólo mencionar a algunos.

Ahora bien, no todos los jóvenes de origen zoque preocupados por el cuidado ambiental o por la identidad zoque son miembros del Centro, por ejemplo, los recién egresados de licenciaturas en ecología, quienes han propuesto alternativas para la conservación de la Selva Negra. Consideran que los habitantes de esta área no conocen la diversidad biofísica y, por tanto, la realización de un inventario de las especies vegetales y animales podría solucionar esta carencia, así como la posibilidad de poder vigilar su utilidad de forma sustentable: "[...] incluso poner así animales que sean amigables con el entorno que ahí mismo no perjudiquen a las milpas y ahí cultivarlos" (entrevista en Rayón, mayo de 2014). En el mismo tenor, se reflexiona de cara a la educación ambiental. En primera instancia consideran que deben trabajarse con los pobladores de la Selva para explicar la importancia de la zona y el valor de los ecosistemas, pero recuperando los conocimientos locales:

Sabemos que la gente en Ocotepec [en la Sierra de Pantepec] tiene un manejo de su territorio con base al clima [...] y de repente llega un manual del gobierno que dice: "-No" [desconociendo los saberes locales]. Pero entonces ¿qué educación tomamos la externa o la local? Ahí debería de ser un experto en esta área que conozca la dinámica del ecosistema o de la comunidad en general, porque un político te puede decir, no sé... ¡maravillas!, pero al final te sirve de poco porque no es experto (entrevista en Rayón, mayo de 2014). 
Así como la preocupación ambiental está presente en el discurso de las generaciones post-erupción, lo está también la búsqueda de una suerte de identidad transregional zoque que el propio Centro fomenta. Se trata de la búsqueda de una identidad que les permita reestablecer lazos entre familias que fueron rotas por la erupción y trazar nuevas dinámicas regionales a través de proyectos culturales que involucren a jóvenes de distintos asentamientos —incluyendo localidades de origen zoque de Los Chimalapas en Oaxaca-y problemáticas diversas. Aquí es donde, de nueva cuenta, la memoria colectiva se pone en marcha para la construcción del espacio vivido en su modalidad de territorio de pertenencia. Al respecto, es importante considerar, de acuerdo con Candau (2005), que si bien no existe la memoria estrictamente individual ni la memoria estrictamente colectiva, ambas participan en las formas sociales de formular un recuerdo.

Estas nuevas dinámicas regionales se construyen no sólo física sino de manera virtual a partir de las redes sociales para quienes tienen acceso a Internet. Así, espacios fragmentados que han caracterizado los espacios zoques configuran actualmente otras formas posibles del territorio. Este aspecto se relaciona también con la condición de exclusión en la cual vive la mayor parte de la generación post-erupción porque no heredará tierras, lo cual genera nuevas dinámicas regionales por migración temporal en el caso de quienes podrán estudiar y de retorno a los terruños de aquellos jóvenes interesados en mejorar la vida de sus comunidades y localidades.

Por su parte, algunos miembros del Centro de Lengua y Cultura Zoque y otros jóvenes aseguran ser conscientes de que sustentar su identidad en el pasado sería reducir sus particularidades presentes. Sin embargo, la constante referencia a un posible origen de lo zoque en la cultura olmeca genera una gran expectativa acerca de la forma en que la sociedad nacional reaccionará al reconocer su especificidad zoque en el contexto de los pueblos mayances de Chiapas.

$\mathrm{Al}$ respecto, los jóvenes han otorgado especial interés a las expresiones artísticas, en términos de que la historia y tradición oral juegan un papel fundamental para el restablecimiento del tejido social después 
del impacto del fenómeno natural. La razón de esto es la propia composición del grupo: académicos, traductores, peritos en lengua zoque y productores radiofónicos. También hay escritores de poesía y prosa, videoastas, artistas gráficos y músicos. ${ }^{16}$ Por ejemplo, desde hace algunos años ha habido interés por parte de los mismos sujetos en producir documentales acerca de los desplazados por la erupción. En 2008 se estrenó "De viceversa”, de Rafael Villegas y Pablo González, que trata de los zoques originarios de Chapultenango que migraron a Guadalajara en 1982, tras seguir a los primeros zoques que en los años sesenta emigraron hacia esa ciudad. De igual forma, Samuel Ávila y José T. Cordero han realizado dramatizaciones en torno a los sistemas de creencias zoques. Saúl Kak, por su parte, ha producido cortos en torno a los problemas ambientales y algunos conflictos políticos suscitados en regiones zoques. ${ }^{17}$

Lo anterior es interesante puesto que los trabajos se exhiben en ocasión de todas las reuniones sociales organizadas localmente por los propios habitantes de origen zoque. Años atrás, aunque hubiera otras producciones, únicamente se presentaba la película realizada por Francisco Urrusti y producida por el Instituto Nacional Indigenista (1985), "Piowachuwe, la vieja que arde", la cual es una dramatización del mito de "la dueña del volcán” y de la erupción de 1982. ${ }^{18}$

Sin proponérselo, la mirada de este cineasta se convirtió en la imagen oficial de la erupción y, paradójicamente, al mismo tiempo reforzó la creencia en torno a la divinidad zoque a la cual se le atribuye el fenómeno natural. ${ }^{19}$

\footnotetext{
${ }^{16}$ Por sólo mencionar algunos de ellos: Fermín Ledesma, Fortino Domínguez, Román Díaz, Magdalena Morales, Mikeas Sánchez, J. Trinidad Cordero, Samuel Ávila, Joaquín Gómez, Roberto Rueda, Miguel y Damián Morales, Pedro Estrada, Humberto Saraoz y Saúl Kak, este último el pintor muralista de Guayabal, Rayón, cuya obra es conocida en Chiapas, Tabasco y Oaxaca, y recientemente participó en la exhibición de artistas gráficos de varios países reunidos en Montreal, Canadá.

17 Ávila, Cordero y Kak son miembros del Centro de Lengua y Cultura Zoque, A.C., aunque sus trabajos han sido signados de manera individual.

${ }^{18}$ Este filme incluye escenas de las condiciones de la población zoque en los refugios de damnificados establecidos en Tuxtla Gutiérrez, Chiapas.

${ }^{19}$ Al respecto, véanse los textos: Pérez y López, 1990; Reyes, 1998; Sulvarán, 2007; Alonso, 2009; Mellanes, 2009.
} 
Por su parte, los procesos de creación musical zoque, que también están vinculados a la memoria colectiva y por tanto son dinámicos y cambiantes de acuerdo con las nuevas realidades, se caracterizan por su coexistencia con diferentes tradiciones musicales. Así, varios jóvenes de Ocotepec, que ahora forman parte del Centro, conformaron un ensamble de ska al cual llamaron "La Sexta vocal", haciendo referencia a la vocal "ï” que existe en la lengua zoque. Una de sus composiciones, hasta ahora la más conocida, es justamente Cowatayu, tambores, como referencia a los ensambles de estos instrumentos que son utilizados en un amplio repertorio tradicional. Huelga decir que estos repertorios musicales tradicionales han caído en desuso a causa de la conversión religiosa al adventismo y sobre todo por las formas de celebrar el culto católico, así como también debido a la migración.

Foto 2. Mural de Saúl Kak en Copainalá

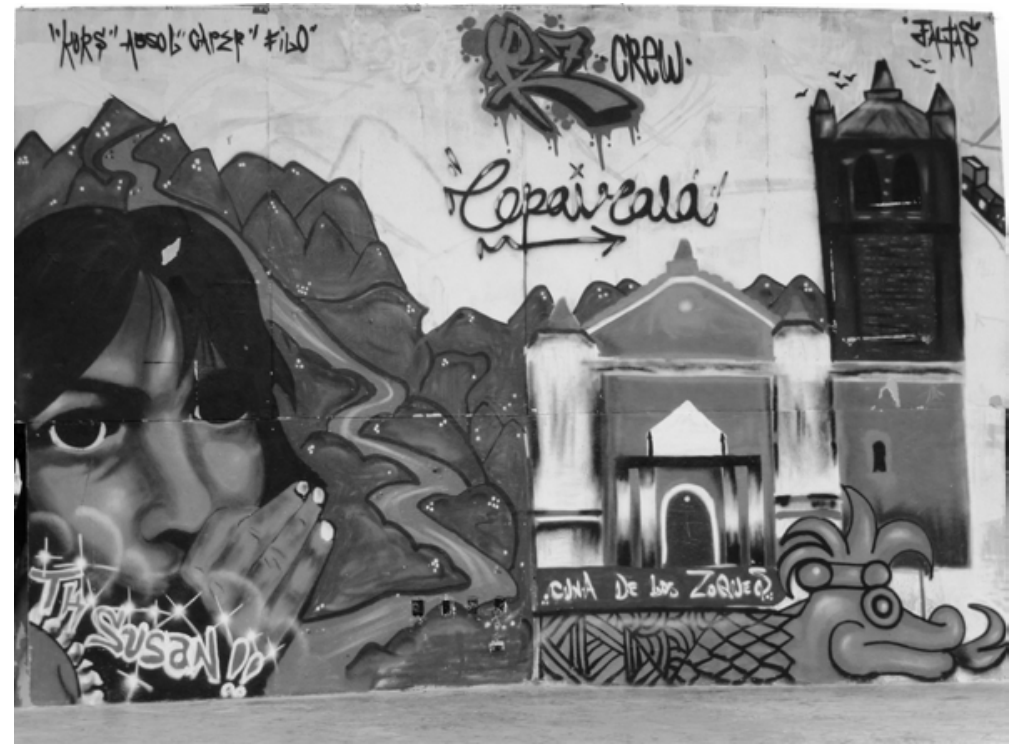

Fuente: Marina Alonso Bolaños, 2014. 


\section{El giro ineludible. Consideraciones finales}

En los últimos años ha habido un creciente interés por la cultura e historia zoque, en parte debido a que las múltiples formas en que se han expresado las dinámicas regionales son quizá más visibles a la mirada externa. Lo anterior ha sucedido también porque la generación post-erupción ha volteado a verse a sí misma no sólo a través de las expresiones artísticas como se mencionó con anterioridad, sino también del trabajo político y académico como el de Fortino Domínguez, a quien he citado acerca de su investigación en torno a las distintas oleadas de migrantes de origen zoque hacia Guadalajara en distintos momentos y por diferentes causas. Asimismo, podemos mencionar la investigación que desarrolla Fermín Ledesma en torno a los conflictos agrarios suscitados en el ejido de Guayabal. Si bien estos investigadores retoman algunos de los planteamientos que otros estudiosos han vertido acerca de los zoques en el contexto de la erupción de El Chichonal, se trata sin duda de exploraciones novedosas que nos conducen a considerar la existencia de un giro en las investigaciones antropológicas e históricas de los zoques. Esto es, por un lado, las investigaciones en torno a los zoques se habían centrado en los zoques como víctimas sin considerar su agencia y diversidad, y esto se relaciona con la emergencia de investigadores de origen zoque como los mencionados.

Foto 3. Generaciones post-erupción

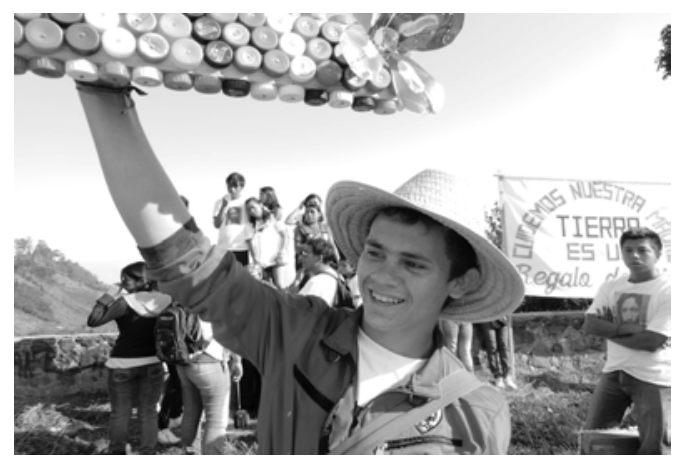

Fuente: Marina Alonso Bolaños 2013. 
Ahora bien, como he indicado en otro lugar, sería erróneo suponer que la región devastada y sus habitantes se han transformado exclusivamente debido a la erupción. Pero tampoco se pueden desdeñar los efectos dramáticos que ésta tuvo, tales como la desaparición de varias localidades con la consiguiente muerte de personas, el desplazamiento forzoso y la afectación de la vida social en general. Después de tres décadas de reubicación, muchos aspectos de la organización social practicados en los antiguos asentamientos de origen zoque se modificaron sustancialmente. Me refiero a cuestiones relacionadas con la conformación de las familias, aspecto de particular preocupación para los padres, quienes indican que anteriormente tenían un mayor control sobre la vida presente y futura de sus hijos. Si bien estos aspectos se antojarían comunes a las relaciones intergeneracionales en general, podemos afirmar que éstas tienen la peculiaridad de plantear abiertamente una ruptura con las formas tradicionales de organización social y política de corte gerontocrático. Por ejemplo, en la Selva Negra y en otras regiones zoques - en donde los ejidatarios se niegan a la participación de sus hijos en la toma de decisiones con respecto a la producción agropecuaria-, las tensiones generacionales se expresan de múltiples formas, por ejemplo, en este movimiento local ecologista. Pero también a través de reclamos velados que únicamente afloran en conversaciones:

Nunca nos dejan [los ejidatarios] decidir a nosotros los jóvenes. Nosotros sabemos la verdad de lo que ha sucedido en nuestros pueblos porque hemos sido testigos (testimonio registrado en Rayón, mayo de 2014).

Por su parte, los jóvenes arguyen que, no obstante la libertad de acción que les ha brindado la educación porque les ha permitido salir de sus localidades, lo cual implica también un manejo distinto de la sexualidad, los adultos prohíben su participación en la toma de decisiones locales porque no son ejidatarios ni todos tendrán acceso a la tierra. Frente a ello, estos jóvenes dejan de proyectarse a futuro como campesinos pese a que los lazos que sostienen con la tierra no son exclusivamente 
económicos. "Los jóvenes sabemos la verdad [...]” no es una afirmación menor sino que expresa la denuncia, si le podemos llamar así, de una falta de reconocimiento a este sector social emergente que no ha sido considerado en términos de lo que fue la erupción de El Chichonal.

Lo anterior expresa la forma en que las generaciones post-erupción viven y construyen las dinámicas regionales. Si bien muchas de las regiones de origen zoque no dejan de permanecer aisladas, a partir del crecimiento de infraestructura carretera y de la ampliación de las rutas de transporte público las localidades han ampliado sus espacios de tránsito y las relaciones con otras regiones y estados del país. Por ejemplo, hay jóvenes que migran a Tabasco, Puebla e Hidalgo para prolongar sus estudios. De igual forma, podemos mencionar que, a pesar de los impactos desfavorables, la erupción trajo consigo varios beneficios a los habitantes de las localidades afectadas, en particular, los zoques dejaron de ser invisibles a la sociedad nacional. Las localidades zoques recibieron servicios públicos, aunque a algunas hayan llegado mucho tiempo después. Por ejemplo, en Nuevo Carmen Tonapac, ubicado en el municipio de Chiapa de Corzo, se pavimentó la primera calle en 2013, es decir, 21 años después de su fundación; de igual forma, Nuevo Francisco León, creado en 1982 en el municipio de Ocosingo, recibió el servicio de energía eléctrica hasta 2003.

Finalmente, la gran movilidad y dispersión de la población zoque a partir del fenómeno natural reactivó la lucha agraria, los conflictos políticos intracomunales y la migración (Alonso et al., 2013). Frente a lo anterior, la memoria colectiva, en ajuste permanente, ha permitido la reproducción de distintos núcleos de población de origen zoque. Así, los casos referidos nos colocan ante problemáticas vinculadas a tensiones entre actores locales que tendrán que ser analizadas a mediano y largo plazos pues, en este proceso, los conflictos y disputas no han estado ausentes entre los miembros de la generación post-erupción. Probablemente, esto derive también del carácter heterogéneo que tuvieron los propios damnificados en tanto que sujetos históricos que actuaron en su momento desde su composición diversa para sobrevivir en condiciones adversas y construir su devenir. 
Foto 4. Conversación por Skype entre zoques de Guadalajara y de Nuevo Carmen Tonapac, Tuxtla Gutiérrez

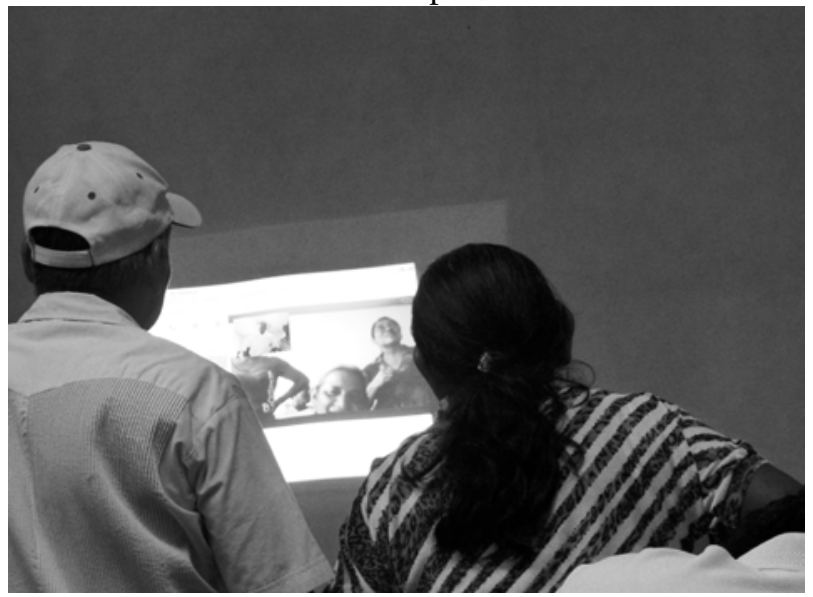

Foto: Marina Alonso Bolaños 2014.

\section{Bibliografía citada}

Alonso Bolaños, Marina, 2006, "Los zoques que dispersó el volcán: hacia una relectura de la erupción del Chichonal”, en Aramoni, Dolores, Thomas A. Lee y Miguel Lisbona (coordinadores), Presencia zoque, Unicach, Cocytech, Unach, UNAM, Tuxtla Gutiérrez, pp 143-150.

Alonso Bolaños, Marina, 2009, "En tiempos de la ceniza en Chichonal o en la Selva, seguimos manifestándonos. Una historia de la organización social y política de los zoques de la Lacandona”, en Estrada Saavedra, Marco y Juan Pedro Viqueira (coordinadores), Los indigenas de Chiapas y la rebelión zapatista. Microhistorias políticas, El Colegio de México, México, pp 133-170.

Alonso Bolaños, Marina, 2011, Los zoques bajo el volcán. Microhistorias de la erupción de El Chichonal, Chiapas, Tesis doctoral en Historia, El Colegio de México, México.

Alonso Bolaños, Marina, 2014, “' $A$ ' los santos también se les lleva su tamalito. La comida tradicional de la Fiesta Grande de Chiapa 
de Corzo", Anthropology of food [Online], en http://aof.revues. org/7559

Alonso, Marina, Javier Gutiérrez, Rodrigo Megchún y Víctor Acevedo, 2013, "Habitar el entorno: experiencias socioambientales en cuatro regiones indígenas en Chiapas", en Eckart Boege (coordinador), Etnografia del patrimonio biocultural de los pueblos indigenas de México, INAH, México (en prensa).

Alonso, Marina, Javier Gutiérrez, Maurico Sánchez, Fermín Ledesma y Alain Giraud, 2015, en Castilleja, Aída y Javier Gutiérrez (coordinadores), Pueblos indigenas y procesos socioambientales, INAH, México (inédito).

Bartolomé, Miguel Alberto, 1997, Gente de costumbre y Gente de razón. Las identidades étnicas en México, Siglo XXI, Instituto Nacional Indigenista, México.

Bonfil, Guillermo, 1995 [1972], "El concepto de indio en América: una categoría de la situación colonial", en Obras escogidas, Tomo I, CIESAS, INI, INAH, México.

Candau, Joël, 2005, Anthropologie de la mémoire, Armand Colin Editor, Paris.

Domínguez, Fortino, 2013, La comunidad transgredida. Los zoques en Guadalajara, Unidad de Apoyo a las Comunidades Indígenas de la Universidad Autónoma de Guadalajara, Guadalajara.

Halbwachs, Maurice, 2004, Los marcos sociales de la memoria, Anthropos, Madrid.

Hoffmann, Odile y Fernando Salmerón (coordinadores), 1997, "Introducción. Entre la representación y apropiación, las formas de ver y hablar del espacio", en Nueve estudios sobre el espacio, Centro de Investigaciones y Estudios Superiores en Antropología Social, México, pp. 13-24.

Lisbona, Miguel, 2003, "Ser zoque, nombrar lo zoque: las dificultades de la clasificación social”, en Millán, Saúl y Julieta Valle (coordinadores), La comunidad sin límites, vol. I, Etnografía de los Pueblos Indígenas de México, Instituto Nacional de Antropología e Historia, México, pp 177-112. 
Lisbona, Miguel, 2006, “¿Existe una cultura zoque? El concepto de cultura en el marco del debate contemporáneo", en Aramoni, Dolores, Thomas A. Lee y Miguel Lisbona (coordinadores), Presencia zoque, Unicach, Cocytech, Unach, UNAM, Tuxtla Gutiérrez, pp. 19-36.

Mellanes, Enrique, 2009, La fiesta del enojo. La tradición oral volcánica de los zoques de Chiapas, Colección Selva Negra, Universidad de Ciencias y Artes de Chiapas, Tuxtla Gutiérrez, Chiapas.

Pérez, Silvia y Sergio López, 1990, Breve Historia oral zoque: Ocotepec, Tapalapa, Tecpatán, Francisco León, Gobierno del Estado de Chiapas-Subsecretaría de Asuntos Indígenas, Tuxtla Gutiérrez, Chiapas.

Pitarch, Pedro, 1995, “Un lugar difícil: estereotipos étnicos y juegos de poder en los Altos de Chiapas", en J.P. Viqueira y M.H. Ruz (editores), Chiapas: Los rumbos de otra historia, UNAM, CIESAS, CEMCA, UdeG, México.

Pitt-Rivers, Julián, 1989, [1970], "Palabras y hechos: los ladinos", en McQuown, N. y J. Pitt-Rivers (editores), Ensayos de antropología en la zona central de Chiapas, INI, México. Reyes, Laureano, 1998, “Testimonio de José Ruedas Sánchez, sobreviviente de la erupción del volcán Chichonal", en Anuario de Estudios Indígenas VII, Instituto de Estudios Indígenas Unach, México, pp. 15-24.

Rosemberg, Florence, 2013, Antropología de la violencia en la Ciudad de México: Familia, poder, género y emociones, INAH, México.

Sulvarán López, José Luis, 2007, Mitos, cuentos y creencias zoques, Universidad Intercultural de Chiapas, San Cristóbal de Las Casas, Chiapas.

Viqueira, Juan Pedro y Mario Humberto Ruz (editores), 1995, Chiapas. Los rumbos de otra historia, Universidad Nacional Autónoma de México, Centro de Investigaciones y Estudios Superiores en Antropología Social, Centro de Estudios Mexicanos y Centroamericanos, Universidad de Guadalajara, México. 